\title{
Parameters identification BLDC motor: Instrumentations and transfer functions
}

\author{
Izza Anshory ${ }^{1,2}$, Imam Robandi ${ }^{1}$, and Wirawan Wirawan ${ }^{1}$ \\ ${ }^{1}$ Institut Teknologi Sepuluh Nopember (ITS), Department of Electrical Engineering, Surabaya, 60111, Indonesia \\ ${ }^{2}$ Universitas Muhammadiyah Sidoarjo, Department of Electrical Engineering, 601271, Indonesia
}

\begin{abstract}
One of the steps that must be taken in optimizing the speed control of the Brushless DC motor (BLDC) Motor is to mathematically model. The purpose of this research is to get the mathematical modeling of BLDC motor with 350 watts of power in the form of transfer function. The method used to obtain the transfer function is to identify the input and output data. The identification is done by designing and placing current sensors, voltages and motor speeds in the prototype BLDC motor speed control. The measured input data includes current and voltage, while the output data is the engine speed (RPM). By adjusting the pulse width modulation value (PWM), a change in the speed of the BLDC motor is affected. From the process of research in the form of instrumentation on hardware prototype and simulation with application program Matlab System Identification Toolbox (SIT), successfully obtained mathematical modeling in the form of transfer function.
\end{abstract}

\section{Introduction}

Optimization is a method used to find the best possible solution of a problem with certain algorithms [1]. One of the studies that need to be done is the optimization of motor speed setting of Brushless Direct Current (BLDCM) as an electric bicycle drive, so that the optimal stability is obtained, such as steady state error reduction and fast transient response [2]. To do the design and optimization, one of the steps that must be done by the researcher is to mathematically model the BLDC motor in the form of transfer function. Information on input and output data from system measurement results [3], is needed to help identify controlled motor systems without risk of damage. There are two approaches in modeling that is modeling based on the theory of knowledge and experimental modeling is done by collecting data such as input and output signals on the system. Modeling with the experimental approach is divided into two, namely parametric and non-parametric approach. The parametric approach is the approach to find out the structure of the model of a system through identification using numerical algorithms. There are four types of model structures used in parametric approaches, such as Auto Regressive with external input (ARX), Auto Regressive Moving Avarage with external input (ARMAX), Output Error (OE), and Box-Jenkins (BJ) [4].

System identification is a process done to get a mathematical model of a system based on input signal data and output. The relation of input and output data is then analyzed by Auto Regressive with external input (ARX) algorithm [5].
The parametric approach with the ARX model structure has the advantage that the physical system is regarded as a black box, so that any kind of component present in the physical system and any kind of material is not at issue and need not be noticed. The modeling process is done through the process of generating test signals and input data input and output using microcontroller atmega 8535. Data sent by microcontroller will be accepted by the software to be identified, so obtained a mathematical model from the plant. The plant identified in this research study is a prototype of BLDC motor rotation speed setting.

BLDC motor is one type of permanent magnet synchronous motor (PMSM) which has many advantages compared to direct current (DC) and induction motor, such as better torque and speed characteristics, high dynamic response, high efficiency and reliability, low maintenance costs, small motor size, no friction in the commutator and the most important of the advantages of BLDC motor is the need for speed and position adjustment [6], the ability to control speed with the change of input voltage [7][8][9].

The purpose of this research is to identify the parameters of BLDC motor, by placing some sensors on the BLDC motor system, to get current, voltage, and speed data. Data measurement results are then analyzed using Matlab's System Identification Toolbox (SIT), so that the output obtained in the form of mathematical models in the form of transfer functions. The identification process is done by several stages: design hardware design, input-output data entry, model structure selection, and identification method. The result of SIT analysis obtained in the form of transfer function

\footnotetext{
* Corresponding author: izzaanshory@umsida.ac.id
} 
is used to perform optimization with artificial intelligent based method.

\section{Identification method}

Fig. 1, explains to identify the parameters in the BLDC motor speed control system by planning the hardware design, testing the input and output. For testing the input is done to know the magnitude of voltage, and current, while for output is to know the amount of rotation speed of BLDC motor. The test result data was analyzed using Matlab System Identification Toolbox. In the analysis, the selected model structure is used along with the selection of criteria for the perfection of the mathematical model produced.

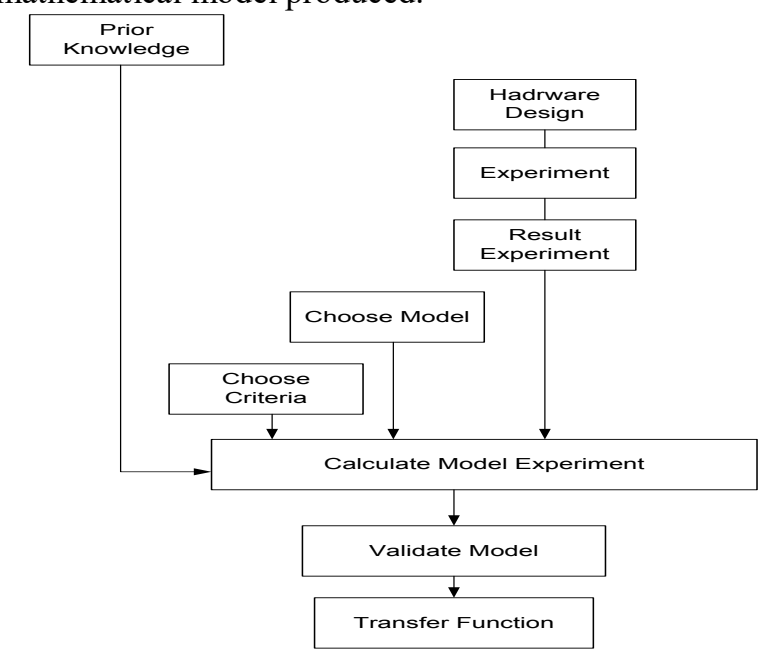

\subsection{Hardware design}

The design configuration to identify the BLDC motor parameters is done by arranging the interface circuit according to Fig. 2.

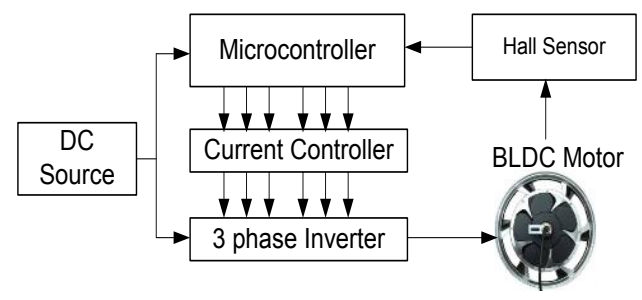

Fig. 2. Block Diagram of BLDC Parameter Identification.

Block diagram of BLDC motor system work is speed is regulated through the amount of PWM value, PWM value is set by programming through arduino microcontroller. To determine the switching order of the inverter driver, arranged through the hall sensor placed on the BLDC motor, after the hall sensor has the rotor position information, it will then be used to switch to six mosfets alternately which will generate $\mathrm{AC}$ voltage, so as to drive the BLDC motor.

\subsection{Design testing to get transfer function}

The test result data is identified to know the parameters by using the System Identification toolbox (SIT) tool, as shown in Fig. 3. SIT is a tool for creating mathematical models, and is based on the collection of input / output data from the system.

Fig. 1. Identification based on parameter estimation.

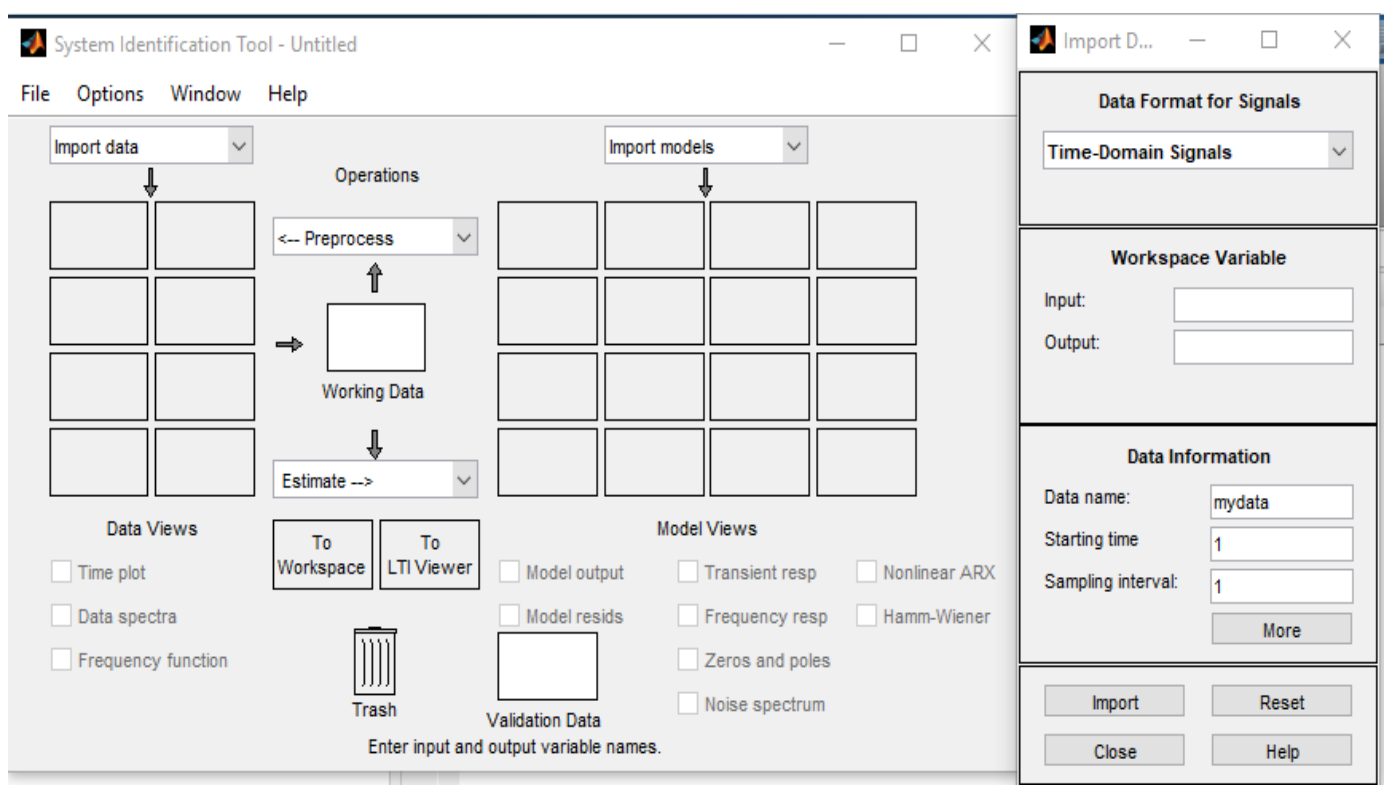

Fig. 3. Design input-output with toolbox identification system.

The mathematical model can be adjusted to the assumed process model setting, until an accurate mathematical model is obtained and matches the input data in the SIT package. Fig .3 shows interface design on Matlab program. On the left side of the interface there is space to enter import data that needs to be inserted in the related window.

\section{Result and discussion}

\subsection{Hardware experiment}

The test procedure is performed to obtain input and output data on BLDC motor speed control system. 
Table 1. The test result data for PWM values 177 to $215 \mathrm{e}$.

\begin{tabular}{|c|c|c|c|c|c|c|c|}
\hline $\mathbf{P W M}$ & $\begin{array}{c}\mathbf{I}_{\mathbf{1}} \\
(\mathbf{A})\end{array}$ & $\begin{array}{c}\mathbf{I}_{\mathbf{2}} \\
(\mathbf{A})\end{array}$ & $\begin{array}{c}\mathbf{I}_{3} \\
(\mathbf{A})\end{array}$ & $\begin{array}{c}\mathbf{V}_{\mathbf{1}} \\
(\mathbf{V})\end{array}$ & $\begin{array}{c}\mathbf{V}_{\mathbf{2}} \\
(\mathbf{V})\end{array}$ & $\begin{array}{c}\mathbf{V}_{\mathbf{3}} \\
(\mathbf{V})\end{array}$ & $\mathbf{R P M}$ \\
\hline 177 & 0,12 & 0,07 & 0,91 & 0 & 10 & 45 & 0 \\
\hline 179 & 0,78 & 0,28 & 0,59 & 45 & 0 & 15 & 346 \\
\hline 181 & 0,3 & 0,25 & 0,3 & 0 & 0 & 0 & 273 \\
\hline 183 & 0,07 & 0,81 & 0,81 & 20 & 0 & 45 & 273 \\
\hline 185 & 0,96 & 0,01 & 1,12 & 30 & 10 & 0 & 280 \\
\hline 187 & 0,04 & 0,15 & 1,44 & 30 & 20 & 0 & 283 \\
\hline 189 & 0,59 & 1,02 & 0,59 & 20 & 45 & 0 & 290 \\
\hline 191 & 0,01 & 0,22 & 0,3 & 0 & 45 & 20 & 296 \\
\hline 193 & 0,3 & 0,7 & 0,54 & 0 & 45 & 15 & 310 \\
\hline 195 & 0,62 & 0,25 & 0,7 & 0 & 45 & 25 & 316 \\
\hline 197 & 0,2 & 0,28 & 1,02 & 30 & 0 & 0 & 323 \\
\hline 199 & 0,2 & 0,01 & 1,18 & 15 & 0 & 0 & 330 \\
\hline 201 & 0,25 & 0,49 & 0,41 & 10 & 45 & 0 & 330 \\
\hline
\end{tabular}

\begin{tabular}{|c|c|c|c|c|c|c|c|}
\hline 203 & 0,07 & 0,52 & 1,49 & 45 & 30 & 0 & 343 \\
\hline 205 & 0,38 & 0,07 & 0,07 & 0 & 10 & 25 & 343 \\
\hline 207 & 0,2 & 0,28 & 0,2 & 0 & 0 & 0 & 353 \\
\hline 209 & 0,46 & 0,65 & 1,31 & 15 & 45 & 0 & 356 \\
\hline 211 & 1,2 & 0,28 & 1,04 & 45 & 0 & 0 & 366 \\
\hline 213 & 0,99 & 0,41 & 0,49 & 0 & 40 & 40 & 370 \\
\hline 215 & 0,01 & 0,09 & 0,96 & 35 & 35 & 0 & 373 \\
\hline
\end{tabular}

\subsection{System identification toolbox}

Test results data that is the current, voltage and motor rotation speed is incorporated into the application system identification toolbox (SIT) contained in the Matlab program. SIT application is used to obtain transfer function based on input and output data as in Fig. 4.

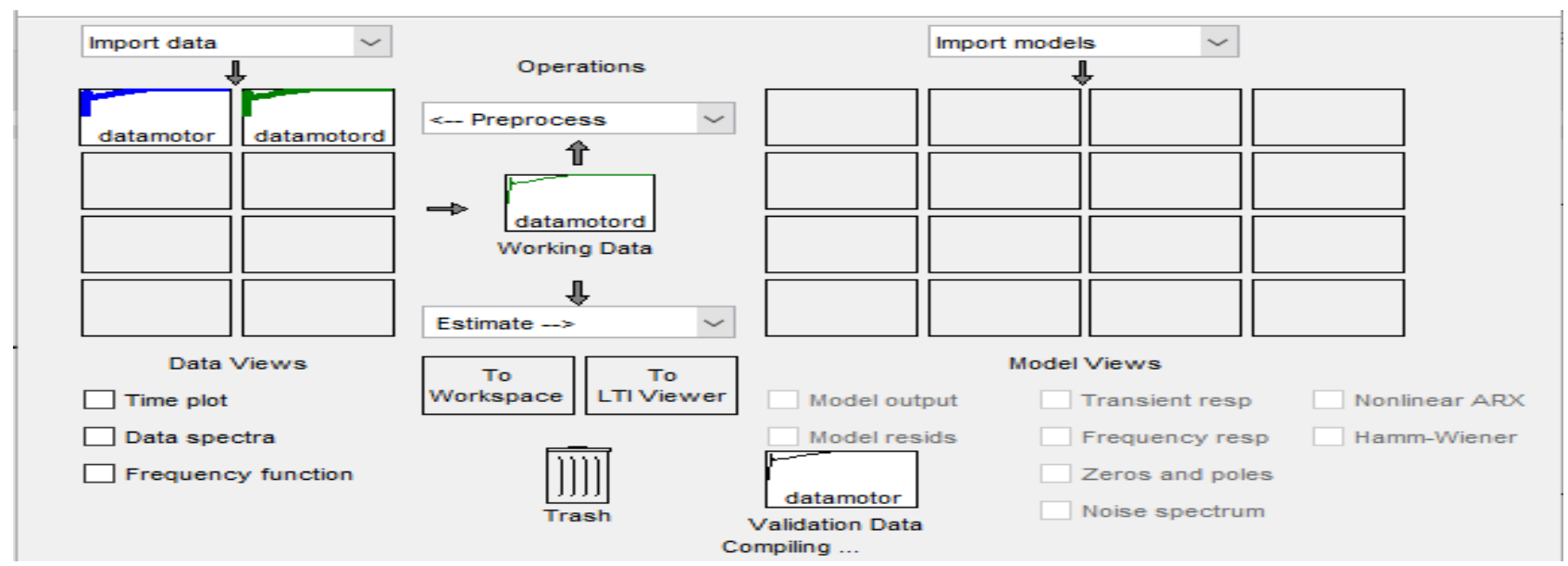

Fig. 4. Results of input and output data are processed with system identification toolbox.

Fig. 4 describes the emerging element data containing the identification system, after processing the model.

Fig. 5, shows the graph for the input and output of the incoming signal in the BLDC motor speed control system.
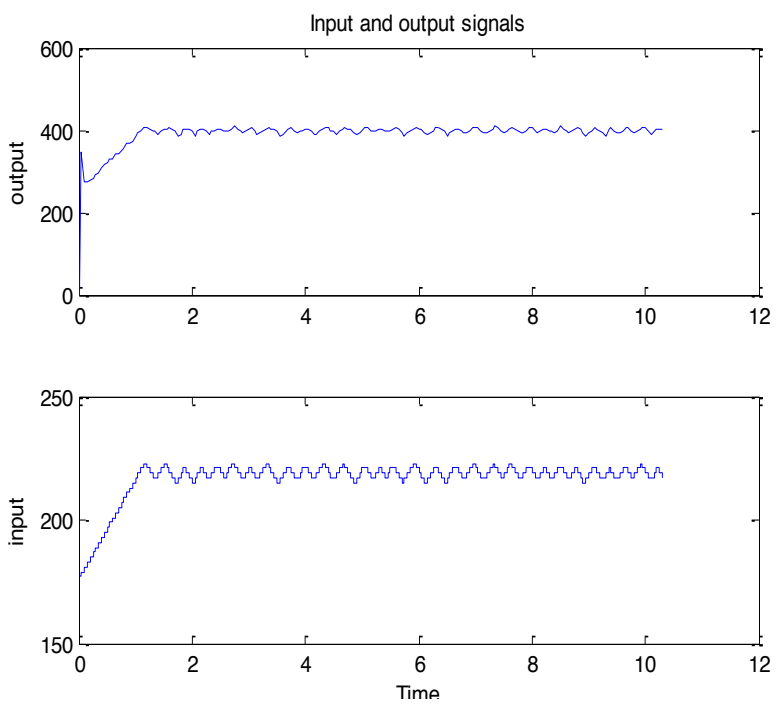

Fig. 5. Input and Output Signal Charts based on Time plotting.

The measurement graph and output model simulation for BLDC motor speed control system is shown in Fig.6.
The model that describes the measured relationship between input and output signals. The output results are partially determined by the input. In most cases, the output is also affected by the interference signal. Shown the relationship between each input and output.

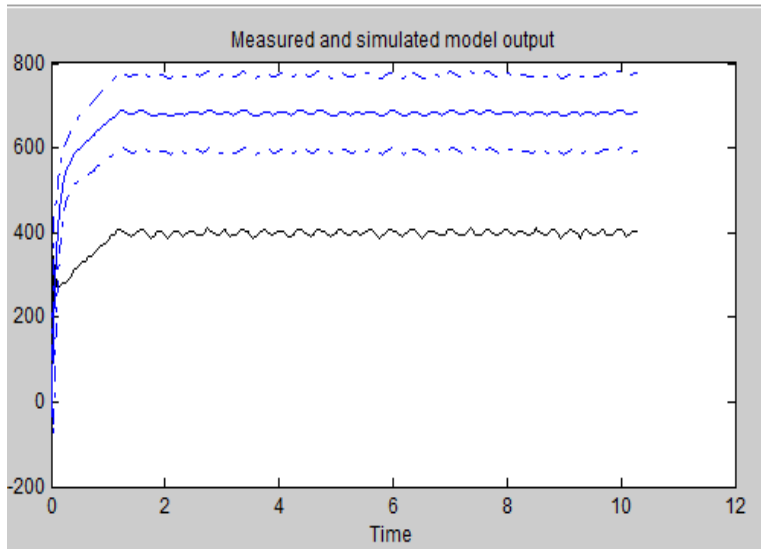

Fig. 6. Graph Measured and Simulated Model Output.

The next step is to perform the identification transfer function by using data estimation based on time domain motor data. Data have an explanation is output data 1,1 and 207 samples. The number of poles is 2 , and the number of zeros is 0 . Results of processing with System Identification Toolbox can be seen in Fig. 7. 


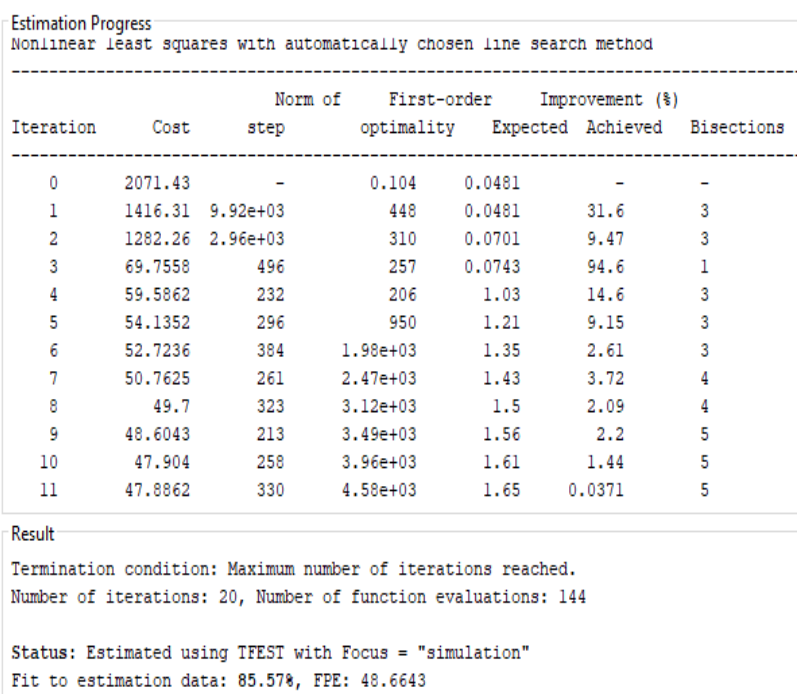

Fig. 7. Estimation progress non linear least square.

Fig. 8 shows the results of a System Identification Toolbox processing in the form of a mathematical model transfer function.

$$
\frac{4787}{s^{2}+132.8 s+1538}
$$

\begin{tabular}{|c|c|c|}
\hline Model name: & \multicolumn{2}{|l|}{ t1 } \\
\hline Color: & \multicolumn{2}{|l|}{$[0,0,1]$} \\
\hline \multicolumn{2}{|c|}{$\begin{array}{l}\text { From input "input" to output "output": } \\
\qquad 787\end{array}$} & $\wedge$ \\
\hline \multicolumn{3}{|c|}{$s^{\wedge} 2+132.8 s+1538$} \\
\hline \multicolumn{3}{|c|}{ Name: tf1 } \\
\hline \multicolumn{3}{|c|}{ Continuous-time identified transfer function. } \\
\hline $\begin{array}{r}\text { Parameteri: } \\
\text { Number }\end{array}$ & zeros: 0 & $v$ \\
\hline
\end{tabular}

Fig. 8. Result mathematical model transfer function.

All these signals are a function of time, and the input value at time t. Often, in the context of identification, only discrete time points are considered, since the measuring equipment typically records the signal only at discrete-time time, spreading in time with the sampling time unit interval $\mathrm{T}$. The modeling problem then illustrates how these three signals relate to each other.

\section{Conclusions}

Result of research to identify parameters system BLDC motor, it is necessary to approach by designing hardware, testing and analysis with System Identification Toolbox. The hardware design is used to obtain accurate data about inputs and outputs. Compared with conventional methods, the identification process can be done more quickly and accurately. To carry out identification with the SIT tool, the correct transfer function type must be selected according to the required response. The accuracy of the calculation of the transfer function needs to be compared with the input data provided to the Matlab application. In addition to the transfer function, Matlab can provide graphical results for input, output and impulse response.

\section{References}

1. S. Mirjalili, Knowledge-Based Systems Mothflame optimization algorithm: A novel natureinspired heuristic paradigm, Knowledge-Based Syst., vol. 89, pp. 228-249, (2015).

2. A. A. A. El-Gammal and A. A. El-Samahy, A modified design of PID controller for DC motor drives using Particle Swarm Optimization PSO, 2009 Int. Conf. Power Eng. Energy Electr. Drives, pp. 419-424, (2009).

3. Jamaaluddin;Imam Robandi, Short Term Load Forecasting New Year Celebration Using Interval Type-2 Fuzzy Inference System (Case Study: Java - Bali Electrical System), in GCEAS 2016, pp. 113. (2016).

4. W. Araydah, T. A. Tutunji, and I. Al-naimi, System Identification for a Liquid Flow Process, no. Imc, (2017).

5. M. Fruk, G. Vujisić, and T. Špoljarić, Parameter Identification of Transfer Functions Using MATLAB, pp. 571-576.

6. U. Bansal and R. Narvey, Speed Control of DC Motor Using Fuzzy PID Controller, Adv. Electron. Electr. ..., vol. 3, no. 9, pp. 1209-1220, (2003).

7. I. Anshory, I. Robandi, and Wirawan, Monitoring and optimization of speed settings for Brushless Direct Current (BLDC) using Particle Swarm Optimization (PSO), in Proceedings - 2016 IEEE Region 10 Symposium, TENSYMP 2016, (2016).

8. A. M. Ahmed and R. Base, Brushless DC Motor Speed Control using both PI Controller and Fuzzy PI Controller, vol. 109, no. 10, pp. 29-35, (2015).

9. B. Das, S. Chakrabarti, P. R. Kasari, and A. Chakraborti, Novel reverse regeneration technique of BLDC motor for capacitor charging, in 2014 International Conference on Control, Instrumentation, Energy and Communication (CIEC), pp. 246-253. (2014) 